\title{
Biobankers: \\ Treat the Poison of Invisibility with CoBRA, a Systematic Way of Citing Bioresources in Journal Articles
}

\author{
Federica Napolitani, Alessia Calzolari, Anne Cambon-Thomsen,,4 \\ Laurence Mabile, Anna Maria Rossi, Paola De Castro, and Elena Bravo²
}

Even though an increasing portion of biomedical research today relies on the use of bioresources, at present biobankers are not able to trace this use in scientific literature and measure its impact with a variety of citation metrics. The "BRIF (Bioresource Research Impact Factor) and journal editors" subgroup was created precisely with the aim to study this issue and to build a standardized system to cite bioresources in journal articles. This report aims at presenting a guideline for Citation of BioResources in journal Articles (CoBRA). The guideline offers for the first time a standard for citing bioresources (including biobanks) within journal articles. It will increase their visibility and promote their sharing.

$\mathrm{I}$ NVISIBILITY CAN BE an asset in many circumstances. In the natural world this supreme form of camouflage can save your life; in a military action it can decide the fate of a battle. But no one in the scientific community of researchers would like to wear an invisibility cloak. On the contrary, the "publish or perish" well-known principle shows how important it is to be out there, in the world of science communication, and of science editing, to be known and to be cited.

However, although researchers, academics, and clinicians can usually see their efforts acknowledged within the research community, biobankers - and the biobanking communitycan rarely receive recognition of their work of setting up and maintaining a bioresource and enjoy the benefits of the impact of their efforts.

Even though an increasing portion of biomedical research today relies on the use of bioresources, ${ }^{1}$ this use is de facto not retrievable. It is usually invisible. At present, biobankers are not able to see precisely how many (and which) studies are based on the use of a specific collection/data set. They cannot clearly identify and trace this use in scientific literature and in PubMed. They cannot measure its impact with a variety of citation metrics. Not yet.

The reason is simply that the tools available today for disseminating and boosting research worldwide are not yet set up to include the specific contribution of bioresources to scientific knowledge.
But what are these tools and how are they related to biobanks?

Since biomedical research is disseminated predominantly in journal articles, this is precisely the level at which the game should be played. It is here that an appropriate set of tools has to be developed and implemented. At the publication level, in fact, the contribution of biobanks is often neglected and/or cited heterogeneously, and this makes its traceability just impossible. ${ }^{1,2}$ Even if researchers would be willing to give the proper credits and report in detail the contribution of the biobank(s) used, they actually have no standards to follow, no publication criteria to apply.

To address this important issue, a "Bioresource Research Impact Factor (BRIF) and journal editors" subgroup formed in 2011 within the BRIF initiative, which is more generally aimed at assessing the value and impact of bioresources and promoting their sharing (http://gen2phen.org/groups/brif-bioresource-impact-factor)." 3,4 The "BRIF and journal editors" subgroup was created precisely with the aim to study this issue and to build a standardized and interoperable system to highlight and cite bioresources in journal articles. ${ }^{4}$

The subgroup, as a first step, performed a series of actions to raise awareness among all stakeholders in the scientific community about the relevance of the subject. Science editors, in particular, were involved from the beginning, because their role was considered essential in the process of setting up standards for publication, and because

\footnotetext{
${ }^{1}$ Publishing Unit, Istituto Superiore di Sanità, Rome, Italy.

${ }^{2}$ Department of Hematology, Oncology, and Molecular Medicine, Istituto Superiore di Sanità, Rome, Italy.

${ }^{3}$ UMR 1027, Inserm, Université Toulouse III-Paul Sabatier, Toulouse, France.

${ }^{4}$ BBMRI-ERIC, Graz, Austria.
}

(C) Federica Napolitani et al., 2016; Published by Mary Ann Liebert, Inc. This Open Access article is distributed under the terms of the Creative Commons Attribution Noncommercial License (http://creativecommons.org/licenses/by-nc/4.0/) which permits any noncommercial use, distribution, and reproduction in any medium, provided the original author(s) and the source are credited. 
leading journals have often proved to be trendsetters in introducing new publication criteria. ${ }^{5}$ In this phase, the subgroup also worked on engaging the science editing network and building collaborative relationships between institutions such as the European Association of Science Editors (EASE), the National Library of Medicine (NLM), the International Committee of Medical Journal Editors (ICMJE), the Committee on Publication Ethics (COPE), the European Association of Health Information and Libraries (EAHIL), the EQUATOR (Enhancing the QUAlity and Transparency Of health Research) network, and others. By presenting this issue in international conferences, launching surveys, and organizing focused workshops of experts at the international level, the subgroup created multiple opportunities of discussion and of exchanges of experiences that were a fruitful source of inspiration.

At the Rome meeting held in June 2013, a consensus agreement was reached about open data sharing in the context of bioresources, ${ }^{2}$ the role of a new journal was discussed (The Open Journal of Bioresources, published by Ubiquity Press for "marker papers" describing bioresources), and an initial format for a standardized citation was agreed on. Marker papers are articles describing the bioresource in detail on the basis of a standardized template. This model of marker papers is already highly successful in other areas such as bioinformatics. The idea of creating a standard to allow traceability of the use of bioresources in journal articles was finally taking form. The foundations of the CoBRA guideline were laid.

But what is the CoBRA guideline and how could it give visibility to biobanks?

As defined in the acronym, CoBRA is a guideline for Citation of BioResources in Journal Articles. ${ }^{6}$ The importance of this guideline is that it offers for the first time a standard for citing bioresources (including biobanks) within journal articles, whenever a study based on the use of a bioresource is published.

The idea behind CoBRA is to go beyond existing unsatisfactory practices, not only by using a univocal name and accurate details of a given bioresource/biobank in defined sections of a journal article, but also by introducing a system of referencing the bioresource in a systematic way that will make possible the traceability of its use. This corrects the heterogeneous and nonstandardized character of reporting that makes retrieving information difficult, as in this way, appropriate information is in the references. According to CoBRA, each individual bioresource used to perform a study should be mentioned in the Material and Methods section of a journal article and should be cited as an individual "reference [BIORESOURCE]" according to a delineated format. ${ }^{6}$ Two examples are provided hereunder for the citation of a biobank and of a registry.

The Italian biobank named "BioBanca Istituzionale (BBI)," a partner in the network BBMRI-ERIC, would be cited as follows:

BioBanca Istituzionale (BBI). Naples, Italy. BBMRIERIC. No. Access: 2; last: April 15, 2014. [BIORESOURCE]

The second example is taken from the report of the Italian National Registry for rare diseases published in $2015 .^{7}$ In this report, all the Italian regional and interregional registries for rare diseases have been cited according to CoBRA, for instance:

Registro Regionale Malattie Rare della Regione Lazio. Lazio. Italia; Last Access: June 30, 2012. [BIORESOURCE]
Other practical examples of alternative ways to reference different types of bioresources (including the example of a bioresource that has been described by a marker paper) are reported in Box 1 in the guideline published in BMC Medicine. ${ }^{6}$

As the name suggests, a "reference" (from the Latin referre, to carry back) connects one object with another, for instance the work of a researcher with a previous work cited in the text. The References, therefore, is the section where information useful for "retrieving" is stored. It is exactly from the citations listed in the References that highly technological bibliographic databases retrieve the information they need for their statistical analysis (like Web of Science, which calculates the Impact Factor in the Journal Citation Report) or for their cross-reference systems (like CrossRef that provides a citation linking network of about 75 million journal articles).

Just imagine the potential advantages of requiring the bioresources to enter these systems. Metrics could determine the influence of a given biobank in the scientific production and in the marketplace. The activity of a biobank could be tracked and valued. It will then be more visible and useful for research. It could help in funding and strategic decisions.

In conclusion, huge economic investments are allocated to human specimen biobanking, which is becoming increasingly important in scientific and medical research, but no specific literature exists for measuring the benefits derived from the use of bioresources, from their application and from the dissemination of the results. ${ }^{1}$ Despite the fact that billions of dollars are spent annually on biobank specimens, ${ }^{8}$ and that biobanking has now a global dimension, ${ }^{9}$ little information is reported about their use in journal articles (and in PubMed) ${ }^{5}$ and value metrics have not yet been defined. ${ }^{10}$

However, standardizing a bioresource citation and placing it in the References section of an article seems more easily said than done. A unique identifier for the bioresource (for instance, the clinical trials registry number) needs now to be worked out as its absence is a handicap both for citation and for traceability as already underlined. However, the different citation patterns proposed in the CoBRA guideline are designed to cover different situations and are open to future developments. The understanding and the support of both editors and researchers are essential in the implementation of CoBRA. The inclusion of CoBRA citation requirements in the Material Transfer Agreements (MTA) could be of great help to ensure that all scientific works based on the samples should cite the resource, and that researchers and prospective authors would comply in accordance with the instructions contained in the guideline.

It will take time but certainly the bases are laid, and CoBRA, with its proposed citation system in journal articles, is at the moment the only solution to increase visibility of biobanks. It will hopefully promote bioresources sharing. Associations such as EQUATOR, a network that works to improve the reliability and value of medical research literature (www. equator-network.org), and EASE, an international association in science communication and editing (www.ease.org.uk), are both supporting CoBRA and will provide updates in their own websites.

\section{Acknowledgments}

The authors acknowledge the support of the following contracts, partially funded by the European Commission Seventh Framework Programme FP7: BioSHaRE-EU project, 
grant agreement number 261433, theme FP7-HEALTH-2010single-stage; BBMRI-LPC project, grant agreement number 313010, and theme FP7-INFRA-2012-1.1.9. Further support was provided by the French infrastructure BIOBANQUES funded through ANR (Agence Nationale de la Recherche). The authors are also grateful to the Italian Ministry of Health (ISS ref. C003) and to the Italian Ministry of Education, University and Research (ISS ref. V16) for the support provided for Italian participation in BBMRI-ERIC.

\section{Author Disclosure Statement}

No conflicting financial interests exist.

\section{References}

1. Mabile L, Dalgleish R, Thorisson GA, et al. Quantifying the use of bioresources for promoting their sharing in scientific research. GigaScience 2013;2:7.

2. De Castro P, Calzolari A, Napolitani F, et al. Open data sharing in the context of bioresources. Acta Inform Med 2013;21:291-292.

3. Cambon-Thomsen A. Assessing the impact of biobanks. Nat Genet 2003;34:25-26.

4. Cambon-Thomsen A, Thorisson GA, Mabile L. The role of a bioresource research impact factor as an incentive to share human bioresources. Nat Genet 2011;43:503-504.
5. Simeon-Dubach D, Perren A. Better provenance for biobank samples. [Correspondence]. Nature 2011;475:454-455.

6. Bravo E, Calzolari A, De Castro P, et al. Developing a guideline to standardize the citation of bioresources in journal articles (CoBRA). BMC Med 2015;13:33.

7. Kodra Y, Ferrari G, Salerno P, Rocchetti A, Taruscio D. Il Registro nazionale e $i$ Registri Regionali e Interregionali delle malattie rare. Rapporto 2001-2012. Roma: Istituto Superiore di Sanità; 2015. (Rapporti ISTISAN 15/16)

8. Rogers J, Carolin T, Vaught J, Compton C. Biobankonomics: A taxonomy for evaluating the economic benefits of standardized centralized human biobanking for translational research. J Natl Cancer Inst Monogr 2011;2011:32-38.

9. Hewitt R, Hainaut P. Biobanking in a fast moving world: An international perspective. J Natl Cancer Inst Monogr 2011;2011:50-51.

10. Watson PH, Nussbeck SY, Carter C, et al. A framework for biobank sustainability. Biopreserv Biobank 2014;12:60-68.

Address correspondence to: Federica Napolitani, $M A$ Publishing Unit

Istituto Superiore di Sanità Viale Regina Elena 299

00161 Rome Italy

E-mail: federica.napolitani@iss.it 